\title{
UTILIZAÇÃO DAS TÉCNICAS DE CFD PARA A ANÁLISE DA CALCINAÇÃO DE GIPSITA EM UM FORNO ROTATÓRIO
}

\author{
R. G. COUTO ${ }^{1}$, E. J. D. JÚNIOR ${ }^{2}$, A. V. A. SANTOS ${ }^{2}$, K. C. MENDES $^{3}$ e M. C. S. \\ SANT'ANNA ${ }^{4}$
}

${ }^{1}$ Escola Politécnica da Universidade de Pernambuco - Campus Benfica, Mestrado Profissional em Tecnologia da Energia

${ }^{2}$ Escola Politécnica da Universidade de Pernambuco - Campus Benfica, Curso de Engenharia Civil

${ }^{3}$ Escola Politécnica da Universidade de Pernambuco - Campus Benfica, Curso de Engenharia de Controle e Automação

${ }^{4}$ Centro de Ciências Humanas, Naturais, Saúde e Tecnologia da Universidade Federal do Maranhão - Campus Pinheiro, Curso de Engenharia de Pesca

E-mail para contato: renato@mekatronik.com.br

\begin{abstract}
RESUMO - O presente trabalho visa estudar o processo de transferência de calor resultante da calcinação de gipsita em fornos rotativos de aquecimento indireto. Para isso, foi realizado uma modelagem computacional com uso do ANSYS FLUENT 17.2, usando a abordagem do Método Euleriano. O Método considera as fases de fluído e sólido como matematicamente interpenetrantes. Após o término dos cálculos das iterações, foi verificado que a modelagem supracitada apresentou um perfil de temperaturas bastante regular, condizentes com trabalhos experimentais anteriores.
\end{abstract}

\section{INTRODUÇÃO}

A gipsita é um mineral não metálico, de larga ocorrência mundial, constituído basicamente de sulfato de cálcio dihidratado (CaSO4-2H2O). Na maioria das vezes, devido a sua formação geológica, seus depósitos minerais estão ligados à fase anidra do sulfato de cálcio, a anidrita (CaSO4), e também a algumas impurezas, como quartzo, carbonatos e argilas (BALTAR et al., 2005).

A produção nacional de gesso, em 2012, foi estimada em 4,5 milhões de toneladas, sendo o Pólo Gesseiro do Araripe (PGA) responsável por 97\% do total (BRASIL, 2014; HENRIQUES JR, 2013).

Tais níveis de representatividade na produção de gipsita e gesso do país conferem ao PGA um papel essencial nesses setores produtivos, tornando praticamente obrigatória que, em qualquer estudo relativo a produção desses materiais, sejam levados em consideração aspectos socioeconômicos da região em que o Pólo se encontra.

$\mathrm{Na}$ atualidade, o processo de calcinação do PGA acontece, em sua grande maioria, em Fornos Marmita Rotativo Horizontal (FMRH). Hoje presente em mais de 120 empresas calcinadoras (SINDUSGESSO, 2014), é conhecido popularmente como "Barriga Quente". Essa tecnologia de fornos foi desenvolvida em 1929 na França, originalmente denominada 


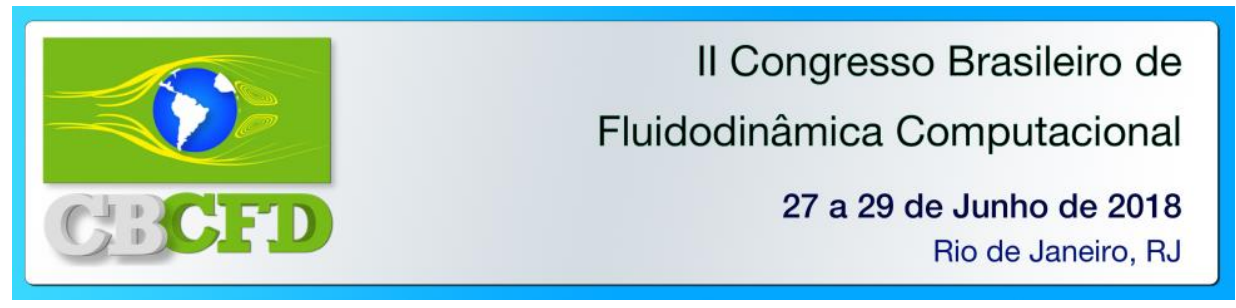

Beau. Seu conceito reside em uma queima lenta e indireta, sendo considerado como um dos melhores processos para se obter um gesso beta de qualidade (DAIRAY, 1999). Empresas francesas como a Grelbex e a Gupsos possuem um longo histórico no desenvolvimento de tais fornos.

Como pode ser visto na Figura 1-1, o forno propriamente dito consiste de um corpo metálico cilíndrico posicionado de forma horizontal. A gipsita moída é alimentada em uma das extremidades do forno. Devido ao movimento de rotação do cilindro em torno de seu próprio eixo e de um conjunto de paletas em seu interior, o material recebido é encaminhado à parte central do forno, onde fica até o final da calcinação. Normalmente, a velocidade de rotação utilizada é baixa, de aproximadamente 5 a 11 RPM (rotações por minuto), para evitar a centrifugação do material, objetivando um movimento de cascata ou catarata.

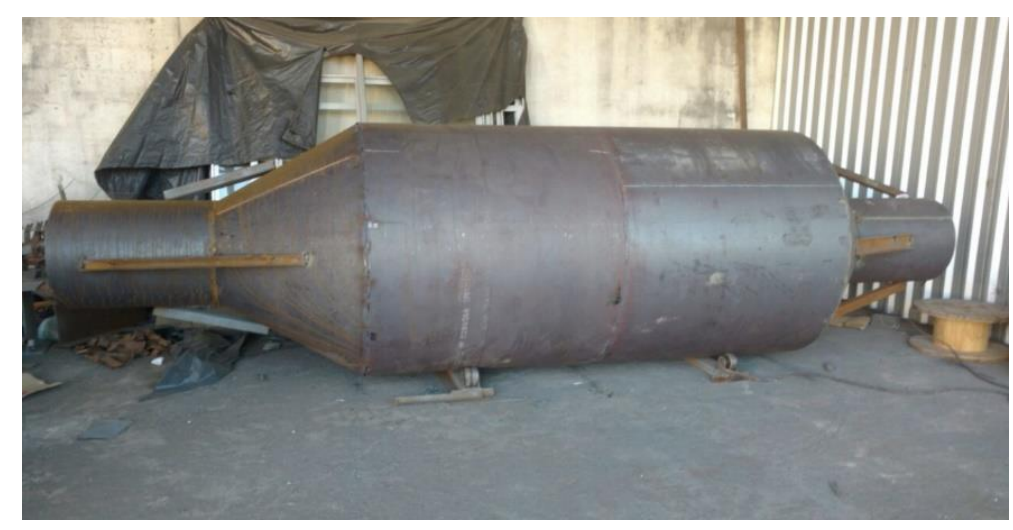

Figura 1-1: Forno real do estudo presente no Pólo Gesseiro do Araripe.

Em geral, o nível de instrumentação e controle adotado pelas empresas é extremamente baixo. Poucas, dentre as 26 maiores calcinadoras, utilizam sensores e sistemas de supervisão e controle para garantir condições padronizadas das variáveis de processo e, dessa forma, obter o controle de performance. Na grande maioria das calcinadoras, a utilização de qualquer sistema instrumentação e controle é inexistente, baseando-se apenas na experiência adquira pelos trabalhadores da região, que desenvolvem métodos rústicos e empíricos de controle.

A junção de todas essas deficiências existentes nos fornos do Pólo ocasiona em um gasto excessivo de energia. A eficiência térmica é o parâmetro que permite avaliar as condições gerais de fornecimento de energia. Nos fornos do Araripe, seu cálculo é obtido pela razão entre a energia fornecida ao processo, calculada pelo consumo de combustível e seu poder calorífico, e a energia teórica (PERES et al., 2001). Por conta do baixo nível de controle utilizado pela maioria das empresas, a eficiência desses fornos se encontra em torno dos 14\% (PERES et al., 2001). Entretanto, calcinadoras que utilizam sistemas de automação, controle e supervisão do processo, além utilizarem recuperação de calor e alimentação automática de cavaco, afirmam alcançar uma eficiência de $45 \%$.

O presente estudo objetiva a compreensão dos processos de transferência de calor, para otimizar a calcinação da gipsita nos fornos da região. 


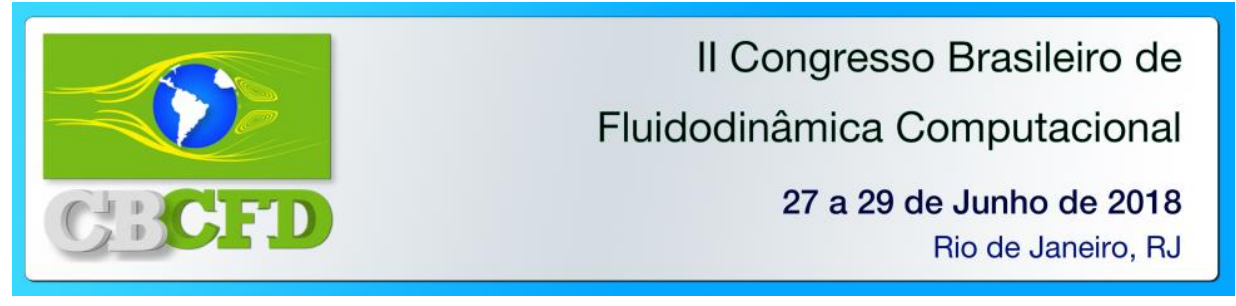

\section{METODOLOGIA}

O software utilizado na modelagem foi o ANSYS FLUENT 17.2 (licença estudantil), tanto para a elaboração da geometria e malha quanto para a instalação das condições de contorno e parâmetros de simulação no setup, já o ANSYS FLUENT 18.2 foi utilizado para os cálculos e o ANSYS CFX 18.2 para a visualização dos resultados. Os cálculos foram realizados em um computador cedido pela Mekatronik Indústria e Comércio de Automação LTDA com configuração de processador Intel® Core ${ }^{\mathrm{TM}}$ i7-4790, SDD de $256 \mathrm{~GB} \mathrm{MHz}$ e memória RAM de 16 GB. A geometria é uma simplificação 3D de um forno industrial de produção de gesso do tipo marmita rotativo horizontal. A modelagem realizada utilizou-se do Método Euleriano, que, além de aplicar as equações de Navier-Stokes, interpreta matematicamente as fases como contínuas, e o acoplamento entre elas é realizado pelo coeficiente de troca de interface e pela pressão.

O sistema de Equações foi resolvido através da utilização do método Phase Coupled SIMPLE para solução do acoplamento pressão-velocidade. Foi utilizada a discretização de segunda ordem para todas as equações, exceto para a fração volumétrica, que foi discretizada pelo método QUICK. O regime de simulação selecionado foi transiente, o time step atribuído foi de $1,0 \times 10^{-4}$ segundos, e o tempo total de simulação foi de 1500 s, sendo necessárias 100.000 iterações para o teste de malha. As propriedades da fase gasosa (ar) foram densidade e viscosidade com valores de $1.225 \mathrm{~kg} / \mathrm{m}^{3}$ e $1.7894 \times 10^{-5} \mathrm{~kg} / \mathrm{ms}$ (ANSYS FLUENT, 2017), respectivamente. Para a fase particulada (gipsita) foram adotados os valores de $2320 \mathrm{~kg} / \mathrm{m}^{3}$ para a densidade da partícula (SANT'ANNA et al., 2017).

Para o forno, o teste de malha foi realizado com 100 mil iterações. A malha utilizada foi composta por elementos hexaédricos e tetraédricos. Os dados estatísticos da malha

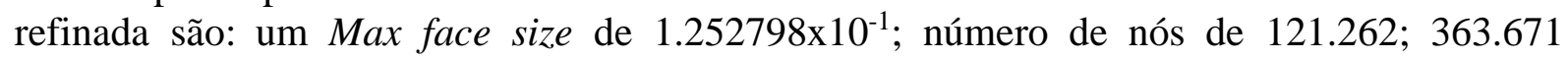
tetraedros e 9.504 hexaedros.

\section{RESULTADOS}

A modelagem desenvolvida e acompanhada em intervalos regulares de tempo, para observar a elevação da temperatura do pó até o final das iterações. No final, a modelagem Euleriana apresenta um comportamento bastante regular, com temperaturas se elevando gradativamente da extremidade do forno até regiões mais próximas do centro. Este fato pode ser observado por meio da Figura 2, abaixo. 

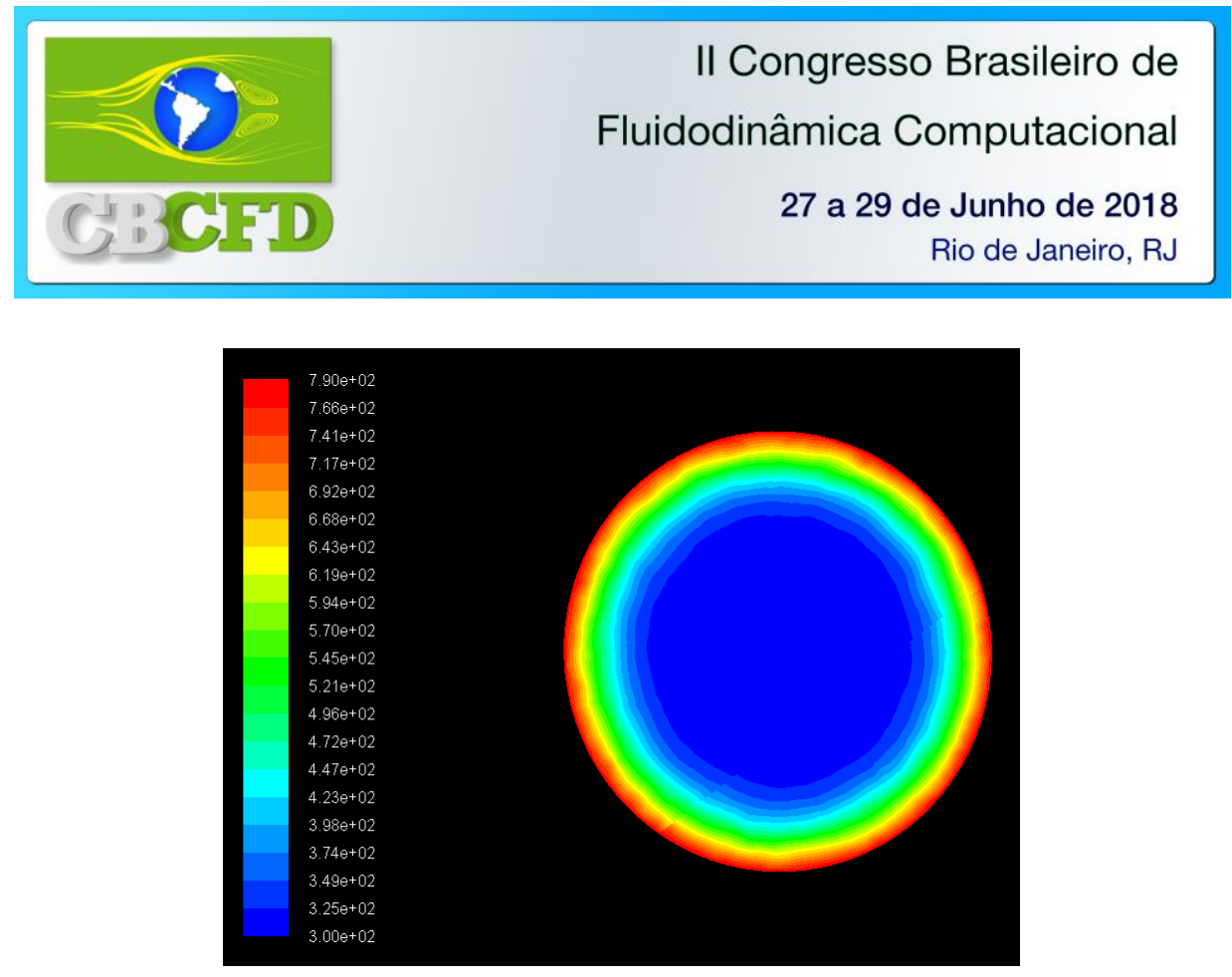

Figura 2 - Perfil de temperatura encontrado ao final da simulação.

Dessa forma, pode-se observar que a transmissão térmica ocorre basicamente na forma de condução nesse sistema. Este comportamento foi encontrado também no trabalho realizado por Urbano (2013) e Almeida (2017), reafirmando a fundamentação existente neste tipo de aproximação.

\section{REFERÊNCIAS}

ANSYS, Theory Guide, Ansys Inc., USA, 2017.

ALMEIDA, Diogo Rodrigues De. Modelagem da Distribuição de Calor e Temperatura, na Fase Transitória, para o Processo de Calcinação de Gesso. 2017.

BALTAR, Carlos Adolpho Magalhães; BASTOS, Flavia de Freitas; LUZ, Adão Benvindo Da. Rochas \& Minerais Industriais. [S.1.]: Centro de Tecnologia Mineral - CETEM, 2005. 449-467 p. Rochas Industriais,minerais industriais, uso e especificações, não metálicos.8572272046.

BRASIL. Anuário Estatístico Do Setor de Transformação de Não-Metálicos. [S.1: s.n.]. , 2014

DAIRAY, Michel. Indirect Contact Rotary Plaster Furnace . [S.1: s.n.]. , 1999

HENRIQUES JR, Mauricio F. Potencial de financiamento de eficiência energética nos setores de cerâmica e gesso no Nordeste. , 2013.

PERES, L; BENACHOUR, M; DOS SANTOS, V A. Gesso: Produção e Utilização na Construção Civil. [S.1.]: Bagaço, 2001. Disponível em: <https://books.google.com.br/books?id=k4b-tgAACAAJ>. .

SINDUSGESSO. Potencialidades do Pólo Gesseiro do Araripe. Simpósio Pólo Gesseiro do Araripe: Potencialidades, Problemas e Soluções Recife: Universidade Federal Rural de Pernambuco, 2014.

URBANO, José Junior. Estudo numérico do processo de calcinação da gipsita em fornos rotativos com aquecimento indireto a óleo. p. $120,2013$. 